\title{
PERCEPÇÕES E PRÁTICAS DE CUIDADORAS COMUNITÁRIAS NO CUIDADO DE CRIANÇAS MENORES DE TRÊS ANOS
}

\author{
VIEWS AND PRACTICES OF COMMUNITY CAREGIVERS IN PROVIDING CARE TO CHILDREN AGED \\ FEWER THAN THREE YEARS
}

\author{
Aida Victoria Garcia Montrone ${ }^{1}$ \\ Rayla Rani ${ }^{2}$ \\ Renata Kazumi Takaesu ${ }^{3}$ \\ Cássia Irene Spinelli Arantes ${ }^{4}$ \\ Márcia Regina Cangiani Fabbro ${ }^{5}$
}

Resumo O objetivo desta investigação foi conhecer as percepções e formas de cuidar de cuidadoras comunitárias de crianças menores de três anos. Trata-se de um estudo exploratório-descritivo com análise qualitativa dos dados. A definição dos sujeitos do estudo foi realizada por meio de mapeamento de possíveis cuidadores comunitários de crianças menores de três anos de idade. Para coleta dos dados, foi utilizada entrevista semiestruturada, com 18 cuidadoras comunitárias, em suas residências. Foi realizada análise categorial temática dos dados, por meio da qual foram identificadas duas categorias: o cuidado na perspectiva do cuidador e formas de cuidar. A primeira categoria evidenciou que o cuidado de crianças menores de três anos é uma tarefa que exige responsabilidade e comprometimento. A segunda categoria mostrou que as cuidadoras priorizam a alimentação, higiene e segurança da criança e consideram o brincar importante para estimular a aprendizagem e a socialização da criança. Este estudo mostrou a necessidade de se propiciar mais espaços de diálogo entre mães, pais, outros familiares, cuidadoras comunitárias e profissionais que lidam com a infância, com o intuito de se ampliar os conhecimentos sobre o cuidado infantil.

Palavras-chave processos educativos; cuidadoras comunitárias de crianças; cuidado da criança.
Abstract The aim of this study was to understand the views and approaches community caregivers use to provide care to children aged fewer than three years. This is an exploratory, descriptive study with qualitative data analysis. Study subjects were defined by mapping possible community caregivers assisting children under three years old. Semi structured interviews were conducted among 18 community caregivers, in their homes. A thematic categorial data analysis was performed, which allowed two categories to be identified: care from the caregiver's viewpoint and ways of caring. The first category showed that caring for children aged fewer than three years is a task that requires responsibility and commitment. The second category showed that caregivers prioritize the children's nutrition, hygiene and safety, and that they consider playing important to drive the kids' learning and socialization process. This study showed the need to provide more opportunities for dialog among mothers, fathers, other family members, caregivers, and community professionals who deal with childhood with the aim to increase knowledge about child care.

Keywords educational processes; community child caregivers; child care. 


\section{Introdução}

A vida do ser humano é repleta de momentos importantes, e a infância é um deles. Nos primeiros três anos de vida da criança, o cérebro possui alta plasticidade e está em crescimento acelerado, o que torna essa etapa ideal para a realização de ações de incentivo e os estímulos visando ao desenvolvimento integral da criança (Zamberlan, 2002).

Sabe-se que o cuidado oferecido à criança menor de 3 anos influencia diretamente no seu desenvolvimento integral. Sendo assim, o desenvolvimento infantil é um assunto ao qual muitos pesquisadores vêm se dedicando a fim de compreender cada vez mais os aspectos que atuam como seus propulsores (Coll, Marchesi e Palacios, 2004).

A construção de um indivíduo depende, em parte, da sua relação com o meio em que vive, pois o crescimento e o desenvolvimento da criança passam por momentos de ordens e desordens nos quais é indispensável a atuação de cuidadores que auxiliem nas potencialidades que as crianças já possuem, de forma a organizar esse ambiente e favorecer o desenvolvimento integral das mesmas (Dessen e Costa Junior, 2005). Coll, Marchesi e Palacios (2004) afirmam que o desenvolvimento integral de uma criança é influenciado por uma inter-relação de fatores físicos, genéticos e ambientais. Esses fatores atuam como uma "tela de fundo para se compreender a contínua interação entre as mudanças que ocorrem no organismo e no seu ambiente imediato" (Aspesi, Dessen e Chagas, 2005, p. 19).

Nesse sentido, na infância, são fundamentais as relações interpessoais para a criação e o fortalecimento dos vínculos afetivos. O Fundo das Nações Unidas para a Infância (Unicef) destacou, em 2008, quão importante é a relação da criança com outro ser humano, pois é através dessa interação que a criança é estimulada e se desenvolve (Coll, Marchesi e Palacios, 2004). Assim, o desenvolvimento integral da criança está vinculado à interação e ao ato de cuidar.

O cuidado representa uma "atitude de ocupação, preocupação, de responsabilização e de envolvimento afetivo com o outro" (Boff, 1999, p. 33). $\mathrm{O}$ zelo destacado por Boff remete à idéia de que o/a cuidador/a da criança é uma pessoa que tem um envolvimento ímpar com a criança cuidada. A Secretaria Municipal de Saúde de São Paulo, com o apoio do Unicef e da Organização das Nações Unidas para a Educação, a Ciência e a Cultura (Unesco) desenvolveu um material de apoio - Toda hora é hora de cuidar (São Paulo, 2003) - sobre a relação entre proteger e cuidar. Essas duas atitudes são responsáveis pela manutenção da vida e da saúde de uma criança.

O cuidado já foi visto apenas como uma atitude materna: as mães eram as principais cuidadoras dos seus filhos e toda a assistência de proteção e de cuidado necessário à criança era oferecida por ela. "A figura feminina era 
eleita responsável por esse cuidado" (Souza, Wegner e Gorini, 2007, p. 169). No contexto da Revolução Industrial, ocorreram muitas alterações na estrutura familiar. O aumento da mão de obra feminina no mercado de trabalho levou a uma mudança na configuração da família e no papel da mulher na sociedade (Muraro e Puppin, 2001; Bruschini e Lombardi, 2003; Bruschini, Ricoldi e Mercado, 2008).

Atualmente, com o modelo nuclear de família em processo de transformação e com as mudanças no papel social da mulher, novos modelos de estrutura familiar vêm sendo criados pela sociedade, com a preocupação de atender às necessidades das crianças. Desse modo, devido à vontade e/ou necessidade de trabalhar, muitas mães delegam a função do cuidado de seus filhos a outra pessoa (Souza, Wegner e Gorini, 2007).

Assim, destaca-se que a responsabilidade do cuidador passa a ter relevância na vida das crianças cuidadas. O cuidador possui uma função singular, ao proporcionar à criança as oportunidades necessárias para que ela alcance, por meio de atividades de estimulação durante o cuidado prestado, o seu pleno desenvolvimento. Nesse contexto, torna-se fundamental a preocupação com o cuidado oferecido às crianças menores de 3 anos, pois necessitam de cuidados mais específicos e especiais (Zamberlan, 2002).

Como em muitas comunidades a demanda por educação infantil é maior do que a ofertada pelo sistema público, as famílias se organizam para procurar na sua comunidade pessoas que se dediquem ao cuidado de crianças, possibilitando o trabalho da mulher fora do lar (Montrone et al., 2010a e 2010b). Na cidade de São Carlos, os bairros Monte Carlo e Jardim Gonzaga, considerados bolsões de pobreza (Campos et al., 2003), são apontados como regiões com alto índice de cuidadoras comunitárias de crianças.

O objetivo deste estudo foi conhecer quem são essas cuidadoras comunitárias, as percepções que elas possuem sobre o cuidado de crianças menores de 3 anos e como praticam esse cuidado. Entende-se como percepção a construção que as mulheres têm sobre o cuidado infantil, ou seja, o que elas pensam com base nas suas experiências, impressões e interpretações das vivências decorrentes desse cuidado.

Consideraram-se, neste estudo, cuidadoras comunitárias as mulheres adultas que cuidam ou já cuidaram de crianças que não os seus filhos e que não tinham formação específica para tal.

\section{Metodologia}

Trata-se de uma pesquisa 6 de natureza qualitativa, de tipo exploratório-descritivo. É qualitativa por incorporar a questão do significado e da intencionalidade como inerentes aos atos, às estruturas sociais e às relações, 
sendo as duas últimas tomadas tanto no seu advento quanto na sua transformação como construções humanas significativas (Minayo, 2006), além de permitir o compartilhamento de experiências, culturas, práticas e percepções dos sujeitos (Chizzotti, 2006).

É exploratória por promover maior aproximação ao problema, a fim de torná-lo mais explícito e com planejamento mais flexível e é descritiva por apresentar a descrição das características de certa população (Gil, 2010).

O estudo foi desenvolvido nos bairros Jardim Gonzaga e Monte Carlo da cidade de São Carlos, estado de São Paulo.

Os sujeitos do estudo foram definidos por meio de um mapeamento de possíveis cuidadores comunitários de crianças menores de 3 anos de idade. Foram entrevistadas 68 pessoas dos bairros estudados que se encontravam em locais muito frequentados por essas comunidades: Centro de Referência de Assistência Social Pacaembu (Cras), Cooperativa de Limpeza e Conservação (Cooperlimp) e Unidade de Saúde da Família (USF) do Jardim Gonzaga. Essas pessoas indicaram 64 possíveis cuidadoras comunitárias de crianças. Não foi apontado qualquer cuidador do sexo masculino.

Primeiramente, foi realizada a tentativa de localização e aproximação das 64 possíveis cuidadoras indicadas, com o objetivo de convidá-las a participar da investigação. Desse total, 18 eram cuidadoras comunitárias; as outras pessoas indicadas ou não eram cuidadoras de criança menores de 3 anos, ou não foram localizadas, ou não pertenciam às áreas de abrangência do estudo. Os critérios adotados para a inclusão dos sujeitos no estudo foram: aceitar participar da pesquisa; ser maior de 18 anos; cuidar ou ter cuidado de uma ou mais crianças menores de 3 anos; e não ser mãe de pelo menos uma das crianças cuidadas.

Para a coleta dos dados, foram realizadas entrevistas com as cuidadoras, utilizando-se roteiro semiestruturado com questões que abordavam o que é ser uma boa cuidadora; o porquê das pessoas a escolherem para ser a cuidadora de seus filhos; os principais cuidados que devem ser oferecidos às crianças; as facilidades e dificuldades durante o cuidado; e a sua rotina de cuidadora junto da criança. O roteiro também continha itens para a caracterização das cuidadoras. Todas as cuidadoras foram informadas sobre o objetivo da pesquisa e assinaram o Termo de Consentimento Livre e Esclarecido.

As entrevistas foram realizadas nas residências das participantes. A média de tempo de cada entrevista foi de 40 minutos, e todas foram gravadas em áudio e transcritas na íntegra. O conteúdo das entrevistas foi analisado com base na análise categorial temática, adotando-se os seguintes passos: ordenação dos dados, classificação dos dados e análise final (Minayo, 2006). Nessa análise, foram identificadas duas categorias: o cuidado na perspectiva do cuidador e as formas de cuidar. 
Esta pesquisa foi aprovada pelo Comitê de Ética em Pesquisa (CEP) da Universidade Federal de São Carlos.

\section{Resultado e discussão}

Do total das 18 cuidadoras comunitárias entrevistadas, a maioria tinha mais de 25 anos $(61,1 \%)$. Em relação à escolaridade, 55,5\% possuíam ensino fundamental incompleto, 33,3\% ensino fundamental completo e $11,1 \%$ eram analfabetas. Em relação ao tempo de experiência com cuidado infantil, duas cuidadoras atuavam a menos de um ano $(11,1 \%)$, seis de um a cinco anos $(33,3 \%)$, seis de seis a onze anos $(33,3 \%)$ e quatro delas atuavam há mais de doze anos $(22,2 \%)$. A maioria das cuidadoras participantes possuía algum grau de parentesco com as crianças $(77,7 \%)$. Quanto ao número de crianças menores de 3 anos cuidadas, 77,7\% cuidavam de uma e 33,3\%, de mais de duas crianças. Vale ressaltar que havia crianças maiores de 3 anos que eram cuidadas pelas cuidadoras, mas que não foram consideradas neste estudo.

A seguir, apresentam-se a descrição e a análise das duas categorias temáticas identificadas.

\section{O cuidado na perspectiva da cuidadora}

A análise dos dados permitiu identificar as percepções das cuidadoras sobre o que é cuidar de crianças menores de 3 anos, as dificuldades encontradas por elas nessa prática, as características que uma boa cuidadora deve possuir, suas motivações para exercer tal cuidado, a razão pela qual são procuradas para cuidar de crianças e a importância/influência da família no cuidado.

Com relação ao cuidar, evidenciou-se que a maioria das cuidadoras acredita que o cuidar de criança menor de 3 anos significa ter responsabilidade, como mostram as falas a seguir:

Eu acho que é pela responsabilidade com a criança. (...) Tem que cuidar direito, pegar uma criança é como se fosse um filho para a gente. Então eu acho que o principal é a responsabilidade (Cuidadora 16).

Outra perspectiva das cuidadoras sobre cuidar das crianças é suprir as necessidades físicas das mesmas, como proporcionar a higienização e a alimentação. Cuidar também é, para algumas, garantir o acompanhamento da criança aos serviços de saúde, em especial quando a criança apresenta febre, conforme os depoimentos a seguir: 
A gente tem que (...) cuidar o suficiente para não deixar essa criança passar falta do alimento, tem que dar muita atenção para a criança. (...) Deve ter os horários dos alimentos, porque senão o crescimento da criança (...), você sabe como é que é... (Cuidadora 11).

Dou banho, dou comida, tudo, comida não falta. (...) Cuidar é dar comida, dar banho, deixar a criança limpinha, levar ao médico quando é preciso, importante levar ao médico quando precisa. Cuidar da saúde da criança (Cuidadora 8).

A gente fica em dúvida: será que não está doente? Eu já sou precipitada, eu já coloco o termômetro; passou de 38 graus, eu já estou correndo. Às vezes, eu chego lá no pronto-socorro e não é nada grave. Eu não dou remédio por conta própria. Para dar remédio tem que ter a autorização de um médico (Cuidadora 6).

E quando fica doente também, ficar atento para correr para o médico, porque você sabe, quando dá uma febre, você sabe que está acontecendo alguma coisa com a criança (Cuidadora 11).

As formas como as cuidadoras veem o cuidar podem ter influência do fato de que muitos profissionais de saúde focalizam quase que exclusivamente os aspectos biológicos nessa faixa etária. Vasconcelos et al. (2009) identificaram, em estudo sobre os significados atribuídos pelos profissionais do Programa de Saúde da Família (PSF) ao cuidar de criança, que, para muitos profissionais de saúde, a atenção à saúde da criança é o acompanhamento do seu desenvolvimento físico.

Mais evidente é o significado dado à alimentação pelas cuidadoras, haja vista que o aspecto nutricional reflete essencialmente o consumo alimentar e o estado de saúde da criança, sendo que ambos dependem do alimento disponível à família, da salubridade do ambiente em que a criança vive e do cuidado dispensado à mesma (Monteiro et al., 2000). Além disso, a grande importância dada à alimentação revela o provável domínio das cuidadoras em relação a esse ato que, historicamente, foi designado à mulher e aprendido nas suas experiências cotidianas. Muitas o citam como uma facilidade no cuidado, conforme a fala de uma cuidadora:

Na hora de dar comida eu acho fácil, dar banho acho fácil (Cuidadora 4).

Ainda sobre o que é o cuidar, as cuidadoras destacaram a importância de estarem atentas para evitar acidentes domésticos, tais como: quedas, queimaduras e afogamentos no momento do banho ou por objetos encontrados no ambiente. Além da segurança física, que inclui o não maltratar a criança, verbal ou fisicamente, preocupam-se com a afetividade e a destacam como 
um fator importante para a vida adulta das crianças, como mostram as falas a seguir:

Não maltratar, não judiar. Porque, senão, a criança cresce revoltada, sabe? Tem muitas crianças como eu vejo que são muito maltratadas, não têm afeto, não têm carinho e hoje estão revoltadas com a vida (Cuidadora 12).

Tomar cuidado para não deixar cair, para não afogar (...), porque as crianças também se afogam (Cuidadora 9).

(...) tomar cuidado para a criança não colocar nada, assim, na boca, porque pode fazer mal, para não ir à rua sozinha (Cuidadora 4).

Olha, eu acho que tem que tomar cuidado para não correr muito, para não acabar se machucando (Cuidadora 11).

Ah, (...) tem que ter cuidado! São indefesos, não sabem se cuidar. Tem que ficar vigiando na banheira. Se quiser brincar (...) deixar (...), mas tem que ficar olhando. Porque eles não sabem se defender (...) [nem] se é certo (...), se é errado. Não sabem se vai machucar (...) se não vai (...), ainda mais nessa idade. Nessa idade tem uma mania de mexer onde não deve. É interruptor, panela (...), coisas assim (Cuidadora 13).

(...) eu acho que a gente tem que ficar sempre olhando, estar atenta para a criança não cair, não se queimar; porque eles apertam tudo, tem que ficar muito perto. É (...), eu acho que é o que eu falei no geral, tomar cuidado para eles não mexerem nas coisas, na cozinha, banheiro, então é isso (Cuidadora 16).

Para as mulheres entrevistadas, uma boa cuidadora de criança precisa ser responsável, ter experiência, dedicação, paciência, bom humor, amor e carinho pelas crianças e, ainda, precisa gostar de realizar a atividade. Tais atributos foram evidenciados nas seguintes falas:

Ai, meu Deus, eu não sei explicar, eu cuido pelo amor, porque gosto e as pessoas também precisam (Cuidadora 1).

Ah, tem que ter cuidado, responsabilidade, porque está em nossas mãos, se acontece alguma coisa, se fica doente, não tem o que fazer, aí é a mãe que tem que ir junto (Cuidadora 2).

Ah, (...) é ter bastante paciência, ter bom humor, é (...) acho que é isso. Ter bastante responsabilidade, só (Cuidadora 4). 
Assim, (...) uma boa cuidadora não é só aquela que dá banho, dá comida e troca. Para cuidar de criança não adianta só fazer isso. Tem que ter amor para saber o que é que ela quer e o que ela não quer. Se você não tiver paciência, calma e amor e afeto você não vai cuidar dessa criança. Principalmente a responsabilidade, porque às vezes a criança está chorando, não é sede não é nada, não está de cocô, não está de xixi, está chorando. É uma dor de ouvido, pode ser uma virose que vem vindo e tem de se ficar atenta. Eu acho que tem que ter amor em primeiro lugar e responsabilidade (Cuidadora 6).

As cuidadoras se preocupam, também, com a imagem corporal que as crianças apresentam às outras pessoas; por esse motivo, elas procuram manter as crianças sempre em boas condições higiênicas e bem apresentadas, pois parece que se importam também com o julgamento feito pelas outras pessoas ao cuidado oferecido por elas às crianças.

(...) deixar sempre limpinho, sempre cheiroso (...), porque aí os outros vão pegar umas crianças que estão fedendo! (Cuidadora 9).

Troco fralda, dou banho (...), até a mãe chegar (...). Coloco na banheira (...), dou banho com sabonete e xampu (Cuidadora 1 ).

Em relação ao julgamento das ações realizadas pelo outro, Soares e Coelho (2008) defendem que mesmo que a comunidade compartilhe da mesma realidade, sempre haverá a apreciação do outro, principalmente quando o descuido é corporificado, ou seja, perceptível por meio da aparência. Os autores em questão denominam esse fenômeno de juízo social do descuido. Neste estudo, foi evidenciado que uma das principais preocupações das entrevistadas é serem apontadas como boas cuidadoras.

Em relação ao motivo pelo qual são procuradas para realizar a atividade de cuidadora, a maior parte das participantes relatou que foi escolhida por ser responsável e por inspirar confiança. Outros motivos foram possuir experiência prévia, gostar de crianças, ser paciente, ser carinhosa, morar próxima à residência da mãe e a necessidade de a mãe trabalhar fora.

(...) acho que porque eles confiam em mim (Cuidadora 12).

(...) ela [a mãe da criança] dizia: "Ai, mãe, eu confio só em você". Então eu cuidei assim

(...). Ah, eu acho que é muito bom porque é tão difícil você confiar (...). Tanta coisa que a gente escuta falar: judiar de criança, esses abusos que têm por aí (Cuidadora 18).

Porque eu acho que elas [as mães das crianças] viam certa responsabilidade já, assim, em mim. E eu gostava muito de crianças também. Aí elas deixavam. Também 
não tinham outras pessoas para cuidar [das crianças]. Aí, elas deixavam comigo (Cuidadora 15).

Acho que porque eu tenho paciência e já faz tempo que eu cuido, não é? Eu não sei ler nem nada, mas, na medida do que eu posso fazer de bom, eu faço! Uma vai contando para a outra... (Cuidadora 1).

Porque eu era vizinha, não tinha outra pessoa, ela trabalhava e eu sempre fui carinhosa com criança e tudo! E ela me escolheu (Cuidadora 4).

Sobre o que as motiva para a realização do cuidado de crianças, foi mencionado o acompanhamento do crescimento e desenvolvimento infantil, enfatizando-se a importância de fazer parte da construção do desenvolvimento intelectual e social da criança.

Então eu acho, assim, que isso aí [o cuidar] é muito bom para o desenvolvimento deles na escola, na sociedade, em tudo (Cuidadora 18).

Saber que tudo o que ela vai ser um dia (...) a gente vê. Para mim, é isso, uma dádiva! (Cuidadora 6).

Lopes et al. (2009) afirmam que as percepções e os conhecimentos das cuidadoras acerca do desenvolvimento infantil são fundamentais para que a criança se desenvolva. Quanto às dificuldades encontradas no cotidiano do ser cuidadora, foram apontados fatores bastante diversificados, como a falta de recursos financeiros, a idade avançada e a falta de paciência. Esses dados referem-se aos familiares, como os avós que realizam o cuidado de seus netos, de forma a facilitar a inserção no mercado de trabalho dos filhos e, assim, melhorar a renda familiar.

E se eu tivesse trabalhando seria melhor, porque ajudava meu marido, e daria mais coisas para os dois, é, coisas materiais (...) (Cuidadora 9).

Não é fácil não, para mim não está sendo fácil. Acho que é pela minha idade mesmo. Eu já não tenho mais tanta paciência (Cuidadora 17).

No que diz respeito aos recursos financeiros, Frota e Barroso (2005) assinalam que a renda familiar é fortemente influenciável no cuidado da criança e que, em algumas famílias, a mulher, além de ser responsável por esse cuidado, também trabalha fora do lar para complementar a renda e, consequentemente, proporcionar melhores condições materiais para a criança. Foi possível identificar cuidadoras que acreditam que a não compreensão da 
criança de alguns aspectos da vida cotidiana são situações difíceis de lidar, como revelado nas falas das cuidadoras a seguir:

(...) porque se eu falo: "Ah, você vai ficar de castigo". Eu ponho ela [de castigo] e ela sai. Eu acho que ela não sabe o que é castigo: ficar sentadinha, não poder sair, acho que ela não sabe (Cuidadora 3).

É difícil na hora que a criança pede alguma coisa que não pode e a criança teima (...). Na hora que você tenta explicar uma coisa para a criança e ela não entende (...), chora, não compreende (...). Ela pega 10 centavos e ela quer ir ao bar comprar sorvete. Aí você fala que 10 centavos não dão para comprar sorvete, ela não quer saber, ela quer ir ao bar comprar sorvete (Cuidadora 4).

O choro constante também foi mencionado como uma dificuldade ao realizar o cuidado da criança.

Ah, tem criança que chora muito, então acho bem difícil quando chora (Cuidadora 12).

Impor limites é uma questão difícil para os adultos que lidam com as crianças, embora seja necessário ao desenvolvimento integral das mesmas. Reações como choro e não aceitação de castigo podem ser minimizadas mediante o diálogo com a criança, de forma que ela compreenda o porquê desses limites. Para Almasan e Álvaro (2006) estabelecer limites faz parte do processo de formação da criança, tanto em relação aos comportamentos apropriados ou não em determinadas situações quanto no que diz respeito aos valores que no futuro embasarão suas decisões sobre o que considera certo ou errado.

\section{Formas de cuidar}

Nesta categoria temática serão apresentadas as formas como as cuidadoras realizam o cuidado das crianças, analisando as principais características desse cuidado. Identificou-se que as formas de cuidar estão voltadas, principalmente, para a alimentação, a higiene e a segurança da criança.

Quanto à alimentação, nota-se que este é um cuidado bastante priorizado pelas cuidadoras comunitárias. É também um assunto que elas relatam frequentemente ao longo da entrevista, dando extrema importância a esse aspecto no cuidado. Ressaltam o valor de manter a criança sem fome, utilizando os mantimentos disponíveis, como mostram as falas a seguir: 
Eu dou pão (...) e quando não tem pão, eu dou bolacha (...) e leite com Nestogeno e o Mucilon [na mamadeira] (Cuidadora 14).

Ah, (...) a comida, ele come de tudo. Ele toma mamadeira de leite com Nescau e come pão, bolacha (...) o que tiver aí (Cuidadora 17).

(...) mama muito, mama cinco mamadeiras por dia, e na mamadeira dela vão cinco colheres de Mucilon com aveia (Cuidadora 11).

(...) a gente dá comida (...). A comida, eu que faço, eu faço Miojo, sopinha com batatinha, (...) mas eu me viro com o que eu tenho (Cuidadora 1).

O estudo de Soares e Coelho (2008) também mostrou que a alimentação é uma dimensão privilegiada do cuidado, tanto na regularidade da oferta quanto na qualidade da alimentação oferecida.

Em relação à qualidade, o presente estudo evidenciou o uso amplo de alimentos calóricos, o que possivelmente se deve à ideia de que criança saudável possui um corpo mais robusto e, também, porque esses alimentos saciam rapidamente a fome da criança. Nos relatos, são notáveis a adaptação e a flexibilidade empregadas pelas cuidadoras quando o alimento mais comumente oferecido ou o alimento planejado para ser oferecido à criança está em falta.

Essa capacidade de adaptação e de maleabilidade, muitas vezes associada à improvisação, pode ser característica das comunidades pobres, nas quais os recursos financeiros e materiais são escassos. Shimabukuro, Oliveira e Taddei (2008) afirmam que é muito importante que os cuidadores de crianças tenham conhecimento sobre alimentação infantil.

Nesse contexto, Molina et al. (2010) destacam que a alimentação está relacionada com a escolaridade materna e que, quando ela é baixa, há maior propensão de a criança cuidada não consumir uma alimentação de boa qualidade, ou seja, é oferecida à criança uma alimentação de baixo valor nutricional e alto valor calórico, apenas para saciar a fome, o que pode levar à obesidade infantil.

Algumas cuidadoras comunitárias se preocupam em oferecer uma alimentação adequada às necessidades de cada faixa etária, além de manter a hidratação necessária. Elas preparam a comida das crianças, tentando incluir alimentos de todos os grupos, como se vê nas falas a seguir.

(...) eu já dou o almoço. Tem dia que é arroz, feijão, salada - porque ela gosta muito de salada - a carne, bastante legumes, bastante verdura, eu dou muito para ela. Água, ela bebe muita água. (...) A gente põe na chuquinha (...) (Cuidadora 6). 
Eles comem de tudo (...). Assim, a minha filha não gosta que dê porcariada, doce, muita coisa fora de hora... Ela não gosta e com razão. Então eu procuro dar uma alimentação saudável para eles. Tomam leite na hora certa. Ela insiste de eles comerem a comida mesmo, arroz, feijão (Cuidadora 18).

Ainda referente à alimentação, fica evidente, nos depoimentos, que a nutrição da criança é um reflexo da alimentação da família da cuidadora, como pode ser comprovado nas falas:

A mesma comida que eu como, que a irmã dela come (...) ela come (Cuidadora 13).

Eu estou com o almoço pronto, ela almoça. A mesma coisa que a gente come: arroz, feijão, salada, carne (Cuidadora 3).

Os dados revelam, ainda, a preocupação das cuidadoras comunitárias em promover a alimentação em horários regulares, conforme exposto a seguir:

(...) meio-dia, meio-dia e meia ela almoça; três horas, eu dou mamadeira; cinco horas, eu dou uma bolacha, alguma coisa, eu dou para ela comer (Cuidadora 3).

Quando é dez horas eu dou a mamadeira, porque a mãe dela já saiu para trabalhar. (...) Sempre, geralmente, das dez até as onze e vinte eu dou uma fruta para ela. Das onze e meia ao meio-dia eu já dou o almoço (Cuidadora 6).

(...) umas sete horas, eu dou uma mamadeira, depois dou uma fruta. (...) Aí dou um almoço com bastante verdura, depois dou uma frutinha; de tarde, dou suco e bastante água; depois, mamadeira para dormir (Cuidadora 10).

Quanto à regularidade da alimentação, mesmo diante da escassez de alimento devido à situação de pauperismo, o cuidado de oferecer o alimento adequado à idade da criança e na hora certa é considerado importante por quem cuida dela (Soares e Coelho, 2008).

A alimentação adequada para a criança nos primeiros anos de vida é fundamental na prevenção de anemia, sobrepeso e baixo peso (Brasil, 2009). O Ministério da Saúde recomenda amamentação exclusiva até os 6 meses e, a partir daí, oferecer alimentos complementares três vezes ao dia. No caso de crianças desmamadas, devem ser oferecidas cinco refeições ao dia, respeitando-se a vontade da criança e priorizando diferentes alimentos ao longo do dia. É importante incentivar o consumo de frutas, verduras e legumes e evitar o açúcar e outras guloseimas nos primeiros anos de vida (Brasil, 2009). 
Neste estudo, evidenciamos que os depoimentos sobre alimentação, na maioria das vezes, vão ao encontro das recomendações para uma alimentação saudável. Apesar das limitações inerentes a sua situação de pobreza, as cuidadoras se esforçam para fornecer alimentos adequados às crianças sob os seus cuidados.

Em relação à higiene, os relatos evidenciam que esse cuidado é essencialmente restrito ao banho e à troca de fralda e de roupa. Nota-se que muitas falas mencionam grande quantidade de banhos dados à criança durante o dia. As cuidadoras relataram que o grande número de banhos decorre das atividades exercidas pela criança, como brincar na areia, ou do clima quente no período do verão.

Ele toma dois, três banhos por dia por causa do calor. Quando ele levanta logo de manhã já dá um banho, aí durante o dia dá outro banho e na hora de dormir tem outro (Cuidadora 11).

A quantidade, assim, depende. Normalmente, de manhã eles já se acostumaram. Eles levantam e já tomam banho para despertar. Depois, o banho para dormir à tarde. Já se acostumaram. E de noite, não dormem sem banho (...). São uns três banhos, assim, normalmente. Mas se é um dia em que [a criança] brincou na areia ou em algum lugar então até extrapola um pouco (...) o banhinho deles na hora certa. Vários banhos por dia... ainda mais no verão (Cuidadora 18).

É, geralmente, quando está muito calor, quando ela acorda, eu já dou um banho, e à tarde é dado outro. E à noite, se estiver muito calor, aí é só lavado o bumbum dela para ela dormir, porque ela ainda usa fralda (...) (Cuidadora 6).

Os vários banhos dados na criança pelas cuidadoras podem estar associados ao que Maranhão (2000) afirma sobre a noção que se tem, em nossa sociedade, de criança saudável como criança limpa e, o inverso seria interpretado como uma criança malcuidada, ou seja, como um descuido de quem cuida. As falas a seguir demonstram a maneira como as cuidadoras dão ou preparam o banho:

Eu dou na banheira, banho normal de criança, com sabonete, shampoo (...) (Cuidadora 9).

Ah, eu esquento a água no fogo, ponho na banheira. Misturo para dar uma esfriada na água (Cuidadora 15).

(...) a cabeça, esfrego o corpinho dela (...), depois enxáguo. Levo para a cama (...), passo talco, pomada... (Cuidadora 14) 
(...) toma dois banhos ao dia, mas não gosta de tomar banho na banheira, gosta de tomar banho no chuveirinho (...) eu sento no vaso e coloco ele no meu colo (...). Ele é muito grande e não fica acomodado na banheira (Cuidadora 5).

As cuidadoras também mencionaram a importância da troca de fraldas, para evitar problemas na pele, e de roupas, para a higienização da criança.

A fralda, a gente troca de três a quatro vezes (...), porque eu não gosto de deixar ela mijada, tanto é que ela nunca assou. Agora a roupa mesmo, a roupa não tem jeito mesmo, né? A roupa sujou, tem que trocar (Cuidadora 6).

(...) são duas trocas de roupa por dia (Cuidadora 5).

Dessa maneira, identificou-se que as cuidadoras comunitárias realizam a higiene da criança principalmente por meio do banho e da troca de fralda e de roupa, não se mencionando outros cuidados. Elas também entendem que a quantidade de banhos depende das necessidades de cada criança e de cada dia.

Os cuidados com a higiene da criança são muito influenciados pela cultura e pelos conhecimentos que as pessoas das comunidades possuem; basicamente incluem banho diário, momentos de troca de fraldas, lavagem de mãos e higiene bucal, que podem se constituir como momentos de prazer e aprendizagem para a criança (São Paulo, 2003).

Outro cuidado que ganha atenção especial das cuidadoras é a segurança física da criança, principalmente quanto ao brincar fora da residência, de acordo com os depoimentos:

Mas aí fico sentada conversando com as vizinhas (...) e a deixo brincando. Depois de brincar mais ou menos uma hora na rua, eu chamo ela para entrar. Aí depois a gente não sai mais de casa. Tranco tudo (...) e aí a gente fica em casa, entendeu? (Cuidadora 13).

(...) é difícil, é muita criança, você vê?! Um vai para a rua, eu vou buscar, o outro vai lá para a quadra, o outro vai lá para cima, é difícil, mas vou fazer o quê?! (Cuidadora 1).

A evidente preocupação dessas cuidadoras com a segurança da criança pode resultar do fato de os bairros analisados no estudo possuírem alto índice de pobreza e de vulnerabilidade social, assim como exacerbados índices de violência e de uso de drogas (Campos et al., 2003).

As atitudes tomadas pelas cuidadoras - não deixar a criança sozinha na rua ou não permitir que a criança tenha contato com pessoas desconhe- 
cidas - podem ser entendidas como uma forma de proporcionar à criança um ambiente seguro, pois, como posto por Winnicott (2005), o ambiente saudável pode ser especialmente provido pela mãe e, neste estudo, também pela cuidadora comunitária.

Outra atividade que as cuidadoras destacam como frequente durante o cuidar da criança é entreter a criança, o que envolve desde assistir televisão até algumas brincadeiras. Em relação ao assistir televisão, explicam que isso se deve à falta de companhia na hora do brincar ou ao espaço reduzido para as brincadeiras.

(...) porque aqui não tem espaço, só tem esse pedacinho e aqui. Então não tem como, no caso, pôr brinquedos para eles. O que eu posso fazer no máximo para eles é deixar assistindo televisão (Cuidadora 16).

(...) eu não posso deixar na rua. Então ele fica dentro de casa. E brincar sozinho ele não brinca (...). então ele fica na televisão (Cuidadora 14).

Algumas cuidadoras incentivam a criança a brincar em companhia de outra criança ou adulto, inclusive a própria cuidadora, possibilitando que a criança desenvolva relações sociais e de amizade com outras pessoas.

Ele brinca com os meus netinhos que vêm aqui, ele adora mesmo brincar. Ele também gosta de brincar muito com um velotrol [triciclo] que ele tem aqui (Cuidadora 11).

(...) na idade dela é mais assim, sabe?, com boneca ela não brinca. Ela pega, olha e joga. Gosta de desmanchar o brinquedo do irmão. Às vezes, ela quer também brincar junto (...), um pouco ele deixa, um pouco eles brigam, eles brincam. Mas a gente procura brincar bastante com ela, conversar, cantar bastante, porque ela gosta de dançar, do jeito dela [risos], mas a gente entende. Eles têm uma piscininha. Então deixo eles brincarem bastante, mas a gente fica olhando (Cuidadora 18).

Ela gosta de brincar com a tia dela de esconde-esconde, boneca. (...) Joguinhos, ela tem os joguinhos de montar. Gosta de música. Ligou, começou a música, ela começa a dançar (Cuidadora 6).

Eu brinco com ele, falo mamãe, papai, canto parabéns, brincando com ursinho, bolinha, até passar o tempo, porque tem que ensinar (Cuidadora 7).

Percebe-se que algumas cuidadoras comunitárias aproveitam as brincadeiras como um momento oportuno para o processo de aprendizado da criança, o que vai ao encontro dos achados de Bustamante e Trad (2007), 
que, em seu estudo sobre o cuidado da criança pequena no contexto familiar, observaram que as cuidadoras veem o brincar como modo de aprendizado e desenvolvimento físico e social da criança.

Finalmente, pode-se dizer que a análise dos depoimentos das cuidadoras comunitárias evidenciou que elas possuem saberes sobre o cuidado infantil oriundos da prática pessoal e familiar, e realizam esse cuidado com responsabilidade, amorosidade e dedicação. Nesse sentido, é necessário que os profissionais da educação e da saúde dialoguem com as cuidadoras de crianças, de forma a compartilharem e ampliarem seus conhecimentos em relação ao cuidado infantil. Segundo Torrezan, Guimarães e Furlanetti (2012), é por meio do diálogo que se dão as oportunidades para a reflexão com as pessoas das comunidades acerca da realidade vivida.

\section{Considerações finais}

Este estudo evidenciou que as cuidadoras comunitárias entendem que cuidar de criança menor de 3 anos é suprir as necessidades de higiene e alimentação e assegurar a proteção afetiva e física da criança, contribuindo, assim, para o seu desenvolvimento físico, intelectual e social. Consideram esse trabalho uma tarefa que exige grande responsabilidade e comprometimento.

As cuidadoras comunitárias têm preocupação com a imagem delas no papel de cuidadoras; por esse motivo, dedicam parte do seu tempo à realização de atividades que mantenham as crianças com boa aparência. Chamou atenção o fato de nenhuma delas ter citado a higienização bucal como uma das atividades do cuidar. Isso revela a importância de ações que promovam a saúde bucal das crianças.

Identificou-se que as cuidadoras comunitárias se preocupam com a segurança física e emocional das crianças. Afetividade, amor e gostar da atividade foram destacados como aspectos fundamentais na prática do cuidar. As principais dificuldades das cuidadoras comunitárias se relacionam aos comportamentos das crianças, como o choro ou a desobediência.

Constatou-se que para as cuidadoras comunitárias o brincar é importante para estimular a aprendizagem e a socialização da criança. Para elas, o cuidar das crianças é motivador, pois se sentem responsáveis pelo futuro das crianças por elas cuidadas.

Este estudo mostrou a necessidade de se realizarem ações de educação em saúde, com o intuito de proporcionar espaços de diálogo entre mães, pais, outros familiares, cuidadoras comunitárias e profissionais que lidam com a infância, a fim de se ampliarem os conhecimentos sobre o cuidado infantil. 


\section{Agradecimentos}

Pela colaboração na coleta dos dados, às estudantes do curso de Graduação em Enfermagem da UFSCar: Ellen C. R. Sobrinho, Fernanda de O. Furino, Flávia C. P. de Abreu, Mariana Soriano, Lígia P. Lopes, Pâmilla N. A. Mania, Rafaella David, Thaíne C. R. Santos e Vanessa de O. Furino.

\section{Colaboradores}

As autoras trabalharam juntas em todas as etapas de produção do manuscrito.

\section{Notas}

1 Universidade Federal de São Carlos, São Carlos, São Paulo, Brasil.

Doutora em Educação pela Universidade Federal de São Carlos.

$<$ montrone@ufscar.br>

Correspondência: Universidade Federal de São Carlos, Centro de Educação e Ciências Humanas, Departamento de Metodologia de Ensino, Via Washington Luiz, Km 235, Caixa Postal 676, São Carlos, São Paulo, Brasil, CEP 13565-905.

2 Universidade Federal de São Carlos, São Carlos, São Paulo, Brasil.

$<$ rayla.rani@gmail.com>

3 Universidade Federal de São Carlos, São Carlos, São Paulo, Brasil.

$<$ renatakazumi@hotmail.com>

4 Universidade Federal de São Carlos, São Carlos, São Paulo, Brasil.

Doutora em Enfermagem pela Universidade de São Paulo. <arantes@ufscar.br>

5 Universidade Federal de São Carlos, São Carlos, São Paulo, Brasil.

Doutora em Educação pela Universidade Estadual de Campinas.

<cangiani@ufscar.br>

6 Trata-se de um trabalho inédito, financiado pela ProEx, e pelo PROEXT/MEC, aprovado pelo Comitê de Ética em Pesquisa (CEP), processo n. 23112.002338/2010-05, da Universidade Federal de São Carlos. 


\section{Referências}

ALMASAN, Daisy A.; ÁlVARO, Alex L. T. A importância do senso de limites para o desenvolvimento da criança. Revista Científica Eletrônica de Psicologia, Garça, ano IV, n. 7, p. 1-7, 2006. Disponível em: <www. revista.inf.br/psicologia07/pages/artigos/ edic07-anoiv-art02.pdf $>$. Acesso em: 12 jul. 2011.

ASPESI, Cristina de C.; DESSEN, Maria A.; CHAGAS, Jane F. A ciência do desenvolvimento humano: uma perspectiva interdisciplinar. In: DESSEN, Maria A.; COSTA JUNIOR, Anderson L. (Org.). A ciência do desenvolvimento humano: tendências atuais e perspectivas futuras. Porto Alegre: Artmed, 2005. p. 19-36.

BOFF, Leonardo. Saber cuidar: ética do humano: compaixão pela terra. 11 ed. Petrópolis: Vozes, 1999.

BRASIL. Ministério da Saúde. Secretaria de Atenção à Saúde. Departamento de Atenção Básica. Saúde da criança: nutrição infantil: aleitamento materno e alimentação complementar. (Série A. Normas e Manuais Técnicos; Cadernos de Atenção Básica, n. 23). Brasília: Ministério da Saúde, 2009.

BRUSCHINI, Cristina; LOMBARDI, Maria R. Mulheres no mercado de trabalho: um retrato dos anos 1990. In: MARUANI, Margaret; HIRATA, Helena S. (Org.). As novas fronteiras da desigualdade: homens e mulheres no mercado de trabalho. São Paulo: Senac, 2003.

BRUSCHINI, Cristina; RICOLDI, Arlene M.; MERCADO, Cristiano M. Trabalho e gênero no Brasil: uma comparação regional. In: COSTA, Albertina de O.; SORJ, Bila; BRUSCHINI, Cristina; HIRATA, Helena. Mercado de trabalho e gênero: comparações internacionais. Rio de Janeiro: FGV, 2008.

BUSTAMANTE, Vânia; TRAD, Leny A. B. Cuidando da saúde de crianças pequenas no contexto familiar: um estudo etnográfico com famílias de camadas populares. Ciência \& Saúde Coletiva, Rio de Janeiro, v. 12, n. 5 , p. 1175-1184, 2007. Disponível em: <www. scielo.br/pdf/csc/v12n5/08.pdf $>$. Acesso em: 12 jul. 2011.

CAMPOS, Silmara E. A. et al. O lazer cotidiano do Jardim Gonzaga: São Carlos. In: ENCONTRO NACIONAL DE RECREAÇÃO E LAZER - LAZER E TRABALHO: NOVOS SIGNIFICADOS NA SOCIEDADE CONTEMPORÂNEA, 15., 2003, Santo André. Anais... Santo André: SESC- Santo André, 2003.

CHIZzOTTI, Antônio. Pesquisa em ciências humanas e sociais. 8 ed. São Paulo: Cortez Editora, 2006.

COLL, César; MARCHESI, Álvaro; PALACIOS, Jesús. Desenvolvimento psicológico e educação: psicologia evolutiva. 2. ed. Porto Alegre: ArtMed, 2004. (Volume 1).

DESSEN, Maria A.; COSTA JUNIOR, Aderson L. A ciência do desenvolvimento humano: tendências atuais e perspectivas futuras. Porto Alegre: Artmed, 2005.

FROTA, Mirna A.; BARROSO, Maria G. T. Repercussão da desnutrição infantil na família. Revista Latino-Americana de Enfermagem, Ribeirão Preto, v.13, n.6, p.996-1000, 2005. Disponível em: <www.scielo.br/pdf/rlae/ v13n6/v13n6al2.pdf>. Acesso em: 12 jul. 2011.

FUNDO DAS NAÇÕES UNIDAS PARA A INFÂNCIA (UNICEF). Situação mundial da infância 2008. Caderno Brasil, Brasília, 2008. 64p.

GIL, Antônio C. Como elaborar projetos de pesquisa. 5 ed. São Paulo: Atlas, 2010.

LOPES, Rita de C. S. et al. Quando eles crescem, eles voam: percepções e sentimentos maternos frente ao desenvolvimento infantil aos 18-20 meses. Psicologia em Estudo, Maringá, v. 14, n. 2, p. 221-232, 2009. Disponível em: <www.scielo.br/pdf/pe/v14n2/ v14n2a01.pdf>. Acesso em: 12 jul. 2011. 
MARANHÃO, Damaris G. O processo saúde-doença e os cuidados com a saúde na perspectiva dos educadores infantis. Cadernos de Saúde Pública, Rio de Janeiro, v. 16, n. 4, p. 1143-1148, 2000. Disponível em: $<$ www.scielo.br/pdf/csp/v16n4/3619.pdf>. Acesso em: 10 jan. 2013.

MINAYO, Maria C. de S. O desafio do conhecimento: pesquisa qualitativa em saúde. 9. ed. São Paulo: Hucitec, 2006.

MOLINA, Maria del C. B. et al. Preditores socioeconômicos da qualidade da alimentação de crianças. Revista de Saúde Pública, São Paulo, v. 44, n. 5, p. 785-792, 2010. Disponível em: <www.scielo.br/pdf/ rsp/2010nahead/1584.pdf $>$. Acesso em: 12 jul. 2011.

MONTEIRO, Carlos A. et al. Da desnutrição para a obesidade: a transição nutricional no Brasil. In: MONTEIRO, Carlos Augusto. Velhos e novos males da saúde no Brasil: a evolução do país e suas doenças. 2 ed. São Paulo: Hucitec, 2000. p. 247-255.

MONTRONE, Aida V. G. et al. Identificação de cuidadoras de crianças menores de três anos de idade em comunidades de São Carlos-SP. In: CONGRESSO PAULISTA DE EXTENSÃO UNIVERSITÁRIA E CONGRESSO DE EXTENSÃO UNIVERSITÁRIA DA UNICAMP, 1. e 3., 2010, Campinas. Anais... Campinas: Book Editora, 2010a. p. 180. Disponível em: <www.proex.unifesp.br/ eventos/.../copex/.../Anais_Copex-2012_ V1_Fim.pdf>. Acesso em: 25 maio 2013.

MONTRONE, Aida V. G. et al. Mapeamento de cuidadores comunitários de crianças menores de três anos nos bairros Jardim Gonzaga e Monte Carlo, São Carlos, SP. In: CONGRESSO DE INICIAÇÃO CIENTÍFICA, 18., 2010, São Carlos. Anais... São Carlos: Universidade Federal de São Carlos, 2010b.

MURARO, Rose M.; PUPPIN, Andrea B. (Org.). Mulher, gênero e sociedade. Rio de Janeiro: Relume-Dumará; Faperj, 2001.
SÃO PAULO. Secretaria Municipal de Saúde. Programa da Saúde da Família. Toda hora é hora de cuidar: manual de apoio. São Paulo, 2003. 104 p. Disponível em: <www. unicef.org/brazil/pt/manualtodahora.pdf $>$. Acesso em: 12 jul. 2011.

SHIMABUKURO, Elaine E.; OLIVEIRA, Mariana de N.; TADDEI, José A. de A. C. Conhecimentos de educadores de creches sobre alimentação infantil. Revista Paulista de Pediatria, São Paulo, v. 26, n. 3, p. 231-237, 2008. Disponível em: <www.scielo.br/pdf/ rpp/v26n3/06.pdf>. Acesso em: 12 jul. 2011.

SOARES, Micheli D.; COELHO, Thereza C. B. O cotidiano do cuidado infantil em comunidades rurais do Estado da Bahia: uma abordagem qualitativa. Revista Brasileira de Saúde Materno Infantil, Recife, v. 8, n. 4, p. 463-472, 2008. Disponível em: <www.scielo.br/pdf/ rbsmi/v8n4/12.pdf>. Acesso em: 10 jan. 2011.

SOUZA, Luccas M. de; WEGNER, William; GORINI, Maria I. P. C. Educação em Saúde: uma estratégia de cuidado ao cuidador leigo. Revista Latino-Americana de Enfermagem, Ribeirão Preto, v. 15, n. 2, mar./abr. 2007. Disponível em: <www.scielo.br/pdf/rlae/v15n2/ pt_v15n2a22.pdf>. Acesso em: 12 jul. 2011.

TORREZAN, Rosiane M.; GUIMARÃES, Raul B.; FURLANETTI, Maria P. de F. R. A importância da problematização na construção do conhecimento em saúde comunitária. Trabalho, Educação e Saúde, Rio de Janeiro, v. 10, n. 1, p. 107-124, 2012. Disponível em: <www.scielo.br/pdf/tes/v10nl/ v10nla07.pdf $>$. Acesso em: 11 jan. 2013.

VASCONCELOS, Eliane N. et al. A normatização do cuidar da criança menor de um ano: estudo dos significados atribuídos pelos profissionais do Programa Saúde da Família (PSF). Ciência \& Saúde Coletiva, Rio de Janeiro, v. 14, n. 4, p. 1225-1234, 2009. Disponível em: $<$ www.scielo.br/pdf/csc/v14n4/a23v14n4. pdf $>$. Acesso em: 12 jul. 2011.

WINNICOTT, Donald. Tudo começa em casa. 4 ed. São Paulo: Martins Fontes, 2005. 
ZAMBERLAN, Maria A. T. Interação mãe-criança: enfoques teóricos e implicações decorrentes de estudos empíricos. Estudos de Psicologia, Natal, v. 7, n. 2, p. 399-406, 2002. Disponível em: <www.scielo.br/pdf/ epsic/v7n2/a21v07n2.pdf>. Acesso em: 12 jul. 2011.

Recebido em 29/11/2011

Aprovado em 13/02/2013 